\title{
Perceived Trajectories of Life Satisfaction Across Past, Present, and Future: Profiles and Correlates of Subjective Change in Young, Middle-Aged, and Older Adults
}

\author{
Christina Röcke and Margie E. Lachman \\ Brandeis University
}

\begin{abstract}
Despite longitudinal stability in subjective well-being across adulthood, many adults perceive self-related change. This study was aimed at identifying differential subjective change profiles in life satisfaction rated for the present, the past, and the future and to examine their associations with sociodemographic variables and changes in adaptive functioning. The authors addressed this aim using Midlife in the United States survey data from 2 measurement occasions $(N=3,631$; age at Time 1:24-75). A cluster analysis was used to identify a continuous high subgroup and an incremental subgroup at both occasions. A 3rd subgroup was labeled present low at Time 1 and decremental at Time 2. Although the average pattern across individual variables suggested stability, up to $60 \%$ of individuals fit profiles depicting perceived change, and some individuals changed subgroup membership over time. After controlling for sociodemographic characteristics, subgroups differed in level and change in biopsychosocial measures of adaptive functioning, with sense of control and social relationship quality showing stronger associations than personality and physical health. Results indicate that a person-centered approach to assessing life satisfaction provides a rich and dynamic picture of individual differences in subjective well-being across the adult life span.
\end{abstract}

Keywords: subjective well-being, life satisfaction, subjective change, person centered, successful development

Subjective well-being (SWB) is typically rated in the moderate to high range (Diener \& Diener, 1996; Pavot \& Diener, 1993) and remarkably stable across the adult life span (Costa \& McCrae, 1994; Diener \& Suh, 1998; Kunzmann, Little, \& Smith, 2000; Mroczek \& Kolarz, 1998). An alternative to examining objective stability and change is to examine individuals' subjective selfrelated perceptions of change. Indeed, people tend to engage not only in social (i.e., interindividual) but also in many temporal (i.e., intraindividual) comparisons when describing themselves (Albert, 1977; Ryff, 1991; A. E. Wilson \& Ross, 2000). These subjective perceptions may reflect implicit theories of development or biases in recall (Ross, 1989; Ryff, 1991) and may serve motivational purposes by providing information on personal improvement from the past or setting goals for the future (Conway, 2005; Robinson \& Ryff, 1999; Ross \& Wilson, 2000).

Christina Röcke and Margie E. Lachman, Department of Psychology, Brandeis University.

This research was supported by National Institute on Aging Grant P01-AG020166 to conduct a longitudinal follow-up of the MIDUS (Midlife in the United States) investigation. The original study was supported by the John D. and Catherine T. MacArthur Foundation Research Network on Successful Midlife Development. We thank Christopher B. Rosnick for valuable comments on a draft and Denis Gerstorf for very helpful advice with the clustering procedure.

Correspondence concerning this article should be addressed to Christina Röcke, who is now at the Department of Psychology, University of Zurich, Binzmühlestrasse 14/11, CH-8050 Zurich, Switzerland. E-mail: c.roecke@psychologie.uzh.ch
Our goal in the present study was to examine types of (linear and possibly nonlinear) subjective change patterns across ratings of one aspect of SWB, namely, life satisfaction, that would provide a more wholistic perspective on the heterogeneity, longitudinal stability, and adaptivity of individuals' perceptions of their own development regarding their evaluation of life. We implemented this aim using a person-centered approach (Gerstorf, Smith, \& Baltes, 2006; Magnusson, 1998), which complements and extends a variable-centered approach in at least two ways: First, it provides a tool for identifying higher order and nonlinear patterns of heterogeneity that are more difficult to uncover using more standard applications (Bergman, Magnusson, \& El-Khouri, 2003). Second, the person-centered approach allows for an identification of subgroup-specific patterns of longitudinal change in profiles of functioning, which in our study represent subjective life satisfaction change profiles (Hertzog \& Nesselroade, 2003).

Whereas previous work using a systemic-wholistic perspective to study successful development identified subgroups of individuals characterized by profiles of successful development and aging across a broad range of variables and subsequently evaluated subgroup differences in SWB (Fiori, Smith, \& Antonucci, 2007; Gerstorf et al., 2006; Ko, Berg, Butner, Uchino, \& Smith, 2007), the present study used the reverse approach: Our focus was on subgroup differences in profiles of subjective stability and change in life satisfaction, and evaluation of profile differences was subsequently conducted by analyzing differences in a range of crossdisciplinary biopsychosocial correlates.

By subjective change, we refer to the profile of life satisfaction for any given individual that is derived from appraisals of past, 
present, and future life satisfaction obtained at any single measurement occasion. This subjective change profile represents individuals' perceived rather than actual longitudinal trajectory. Others have referred to this as personal time perspective (Bortner \& Hultsch, 1972) or subjective lifetime (Fleeson \& Baltes, 1998). We differentiate this notion of subjective change from objective change, which refers to profiles of present life satisfaction obtained at different measurement occasions. We investigated subgroup differences in associations with sociodemographic as well as biopsychosocial indicators of adaptive functioning as a means of exploring the functional utility of distinguishing subgroups according to differential patterns of subjective life satisfaction change.

\section{Subjective Versus Objective Self-Related Change}

Asking individuals repeatedly to assess their current life satisfaction, as done in longitudinal studies, provides information on the actual time-related consistency of life satisfaction in concert with changes in other domains and has, in older adulthood, given rise to such phenomena as the so-called well-being paradox, referring to the apparent mismatch between the relative stability in well-being in the context of losses in domains such as cognition and health (e.g., Kunzmann et al., 2000).

The meaning of concurrent assessments of SWB, however, can differ as a function of whether they are higher or lower than retrospective or prospective views of the past and the future (Bortner \& Hultsch, 1972, 1974; Fleeson \& Heckhausen, 1997). When thinking back, individuals may reconstruct their past standing on a certain characteristic based on their implicit theory about stability versus change in this characteristic (Ross, 1989). In some situations or with regard to certain characteristics, recalling one's past as negative may serve the purpose of enhancing the present, especially in domains that are highly self-relevant (Ross \& Wilson, 2000; see also Bryant, Smart, \& King, 2005; Sedikides \& Gregg, 2008). In addition, remembering one's past can affect current goal setting and pursuit (Conway, 2005; Sutin \& Robins, 2008). When thinking ahead, most individuals expect things to change in a positive manner (Aldwin, Sutton, \& Lachman, 1996; Newby-Clark \& Ross, 2003; Ryff, 1989; Woodruff \& Birren, 1972), even though the magnitude and direction of change depends on the domain under study and temporal distance between the retrospective and prospective time points compared with the present (Broemer, Grabowski, Gebauer, Ermel, \& Diehl, 2008; McFarland, Ross, \& Giltrow, 1992). Similar to constructions of the past, anticipation of the future is also linked to goal-relevant behavior (Baumgartner, Peters, \& Bagozzi, 2008).

Self-reported change as implied from the pattern of concurrent ratings of the past, present, and future complements the classical longitudinal change perspective by providing insights into the subjective representation of self-consistency versus self-change (i.e., gain or loss; see also Thorne \& Klohnen, 1993). Apart from the goal-relevant motivational implications of both retrospective and prospective ratings of personal characteristics, individual differences in such subjective change in life satisfaction are also related to other SWB and personality characteristics (Pavot, Diener, \& Suh, 1998; see also Fleeson \& Baltes, 1998; Keyes \& Ryff, 2000). Average subjective change trends, however, may not represent the range of possible individual trajectories and types of change profiles (Bortner \& Hultsch, 1972; Lachman, Lewkowicz,
Marcus, \& Peng, 1994), which is why the focus of the present study was on variations in profiles of subjective life satisfaction change.

\section{Age and Sociodemographic Differences in Profiles of Subjective Life Satisfaction Change}

Research on the characteristics of happy individuals mainly focused on average levels and average (objective) change in SWB. It is not known, however, whether variables identified as correlates of these average SWB parameters show similar associations with individual differences in subjective assessments of stability and change.

Sociodemographic characteristics, such as income and gender, tend to be only weakly or even unrelated to average levels of life satisfaction (Diener \& Suh, 1998; Marmot, Ryff, Bumpass, Shipley, \& Marks, 1997; Ryff \& Singer, 1998), and very small associations have been found regarding age (Diener \& Suh, 1998; but see also Mroczek \& Spiro, 2005). In contrast, age may be related to subjective self-related changes as a function of age-specific stereotypes (Heckhausen, Dixon, \& Baltes, 1989) or objective age-related changes in the availability of resources and constraints in various life domains (Baltes, Lindenberger, \& Staudinger, 2006). Reflecting on one's past and future in addition to the present is likely to trigger considerations of past experiences and age-graded normative future changes and developmental tasks. Together with a shifting focus from growth to an orientation on maintenance and prevention of loss from young to later adulthood (Freund, 2006; Lachman, 2004), and a gradual shift from an unlimited to a more limited future time perspective with increasing age (Carstensen, Isaacowitz, \& Charles, 1999; Heckhausen et al., 1989), these processes might contribute to greater age differences and qualitatively different expectations of change in younger as opposed to older adults.

Apart from age, marital status is important for life satisfaction given that spouses represent a major source of social support (e.g., Diener \& Seligman, 2002). Married individuals may thus be more likely to report stable high life satisfaction or to expect the future to bring even higher satisfaction than unmarried individuals. Given their weak relationships with average levels of SWB, income, gender, and education were not expected to show strong relationships with subjective change profiles.

\section{The Adaptive Value of Different Types of Profiles of Subjective Life Satisfaction Change}

Identifying antecedents and/or correlates of subjective change profiles may be useful in understanding the self-regulatory function of these diachronic conceptions (Staudinger, Freund, Linden, \& Maas, 1999). If different types of profiles in subjective life satisfaction change represent meaningful individual differences, they should be associated with differences in key aspects of psychological functioning and health. Subjective stability across one's lifetime may be associated with more positive outcomes because it satisfies the need for self-consistency, whereas subjective improvement in life satisfaction from one's past to the future may be adaptive as it implies self-enhancement (Jones, 1973; Keyes \& Ryff, 2000). 
Several domains of psychological functioning have been proposed to be components of successful development and adaptive functioning, such as high levels of health, cognition, social support, sense of control, and certain personality traits (Ko et al., 2007; Rowe \& Kahn, 1997; Smith \& Baltes, 1997). For the purpose of examining and evaluating different subjective change profiles, we draw on this previous work to define greater as opposed to lower adaptivity of a subjective change profile as being related to higher in contrast to lower levels of desirable characteristics such as good health, social support, certain personality characteristics (extraversion, openness, agreeableness, and conscientiousness), as well as cognitive functioning and optimism, and lower levels of less desirable characteristics such as neuroticism.

All of these indicators of adaptive functioning tend to be more strongly related to average levels of SWB than do sociodemographic variables (Staudinger, Fleeson, \& Baltes, 1999). Very happy and satisfied people report high quality social ties, high extraversion and agreeableness, low neuroticism (Diener \& Seligman, 2002; Myers \& Diener, 1995), and a high sense of control (Lachman \& Firth, 2004; Rodin, Timko, \& Harris, 1985). Furthermore, changes in life satisfaction can have an impact on subsequent changes in older adults' perceptual speed (Gerstorf, Lövdén, Röcke, Smith, \& Lindenberger, 2007). Beyond their relationships with average levels and change of life satisfaction, individual differences in these personal resources and in dispositions regarding the outlook on life (e.g., optimism) are likely to play a role in individuals' subjective conceptions of self-related change.

\section{The Present Study}

The aim of the present study was to examine types of subjective change profiles in life satisfaction using a person-centered approach, including sociodemographic and biopsychosocial antecedents, correlates, and outcomes of profile differences. We implemented this aim using a national sample of adults ranging in baseline age from 24 to 75 years, who provided ratings of their past, present, and future life satisfaction at two measurement occasions spaced on average 9 years apart.

We pursued three central research questions: (a) Which types of profiles reflecting subjective change in life satisfaction from past to present to future can be identified, and are they consistent at each measurement occasion? (b) Are there conceptually meaningful associations between these profiles and sociodemographic variables as well as biopsychosocial indicators of adaptive functioning (i.e., concurrent levels and longitudinal change)? (c) Are sociodemographic and biopsychosocial correlates related to consistencies versus inconsistencies in subgroup membership between Time 1 (T1) and Time 2 (T2)?

On the basis of the previous research summarized above, we expected the majority of individuals to show a type of subjective change profile representing improvement, at least from the present to the future. Furthermore, young adults were expected to more frequently belong to subgroups showing patterns of continued growth from past to present to future, whereas older adults would show high but stable (past to present) or even slightly declining (present to future) profiles of life satisfaction. Married individuals were thought to belong to subgroups with high and stable or incremental (i.e., optimistic) patterns of subjective life satisfaction change. ${ }^{1}$ Other sociodemographic variables were expected to show little relationship with profiles per se. We explored, however, whether individuals experiencing negative (positive) changes in marital status and income from $\mathrm{T} 1$ to $\mathrm{T} 2$ (compared with no change) would belong to subgroups displaying less (more) favorable profiles of subjective life satisfaction change at $\mathrm{T} 2$.

With regard to subgroup differences in levels and longitudinal change in biopsychosocial functioning, we expected subgroups with high and stable rather than decremental profiles of subjective change to have higher concurrent levels and longitudinal stability in sense of control, health, social support, and positive personality characteristics. Subgroups with subjective change profiles representing incremental life satisfaction were expected to show average rather than high levels of adaptive functioning because perceptions of self-related increments on the one hand provide a sense of improvement but on the other hand contrast with the need for self-consistency. The reverse would be true for stable but very low levels of perceived life satisfaction, which would satisfy the need for self-consistency but violate the need for self-enhancement.

Lastly, we hypothesized that individuals who shift from a subgroup with a stable high or at least partially growth-oriented profile of subjective life satisfaction change to a less favorable profile (e.g., decremental at least from present to future, or stable at low levels) between $\mathrm{T} 1$ and $\mathrm{T} 2$ would show objective longitudinal losses in biopsychosocial indicators of adaptive functioning.

\section{Method}

\section{Participants}

The sample consisted of participants from the longitudinal Midlife in the United States Survey (MIDUS). A national sample of 7,120 noninstitutionalized adults in the 48 contiguous states with at least one telephone was selected using random digit dialing in 1995-1996 (T1; Brim, Ryff, \& Kessler, 2004). Although a national sample, it was slightly positively biased compared with the Current Populations Survey data (U.S. Census Bureau, 2008), underrepresenting minorities and those with low income and education. This is likely due to use of a telephone survey and a lengthy self-report questionnaire. A total of $75 \%$ of the original sample participated in the follow-up conducted an average of 9 years later (T2).

For the present study, the 3,793 participants who provided complete data on the three life satisfaction variables at both measurement occasions were included. Of these, 162 cases (4.3\%) were excluded from the final analyses because of outlying values $(>3 S D)$ on one or more of the life satisfaction variables (range:

\footnotetext{
${ }^{1}$ Conceptually, the same expectation would hold for individuals in stable relationships who are not married. In MIDUS, the only information beyond marital status was whether individuals were living with somebody. In the present sample, only very few individuals ( $n=140$ and $n=120$ at $\mathrm{T} 1$ and T2, respectively) reported to be living with somebody without being married. Patterns of cluster subgroup differences did not differ when restricting the analysis to "married" versus "not married" individuals compared to also including those "living with somebody" into a with partner versus without stable relationship category. Because of the very small number of individuals reporting living with somebody without being married and the similarity in results using either categorization, we report findings with regard to the "married" versus "not married" distinction.
} 
$n=20$ to 61 across items), resulting in a final sample of 3,631 MIDUS respondents (see description of statistical procedures below for more details). ${ }^{2}$ At T1, participants' ages ranged from 24 to $75(M=47.01, S D=12.24)$ and $54.6 \%$ were female. The majority were Caucasian $(94.0 \%)$ and married $(72.9 \%)$, and $37.3 \%$ had attained a baccalaureate or advanced degree.

\section{Dropout Analyses}

Comparison of the longitudinal sample used in the present study with individuals dropping out after T1 showed positive selection, as expected. At baseline, dropouts were slightly but not significantly older than the longitudinal sample $(M=47.16$ years, $S D=$ 14.05 vs. $M=46.99$ years, $S D=12.23)$, less likely to have a college degree $(28.9 \%$ vs. $44.9 \%)$, less likely to be female $(47.8 \%$ vs. $54.6 \%$ ), and reported lower subjective health on a 5-point scale (dropout: $M=3.31, S D=1.04$; longitudinal: $M=3.66, S D=$ 0.91). The dropouts reported lower life satisfaction for the present $(M=7.59, S D=1.83)$, the past $(M=7.19, S D=2.05)$, and the future $(M=8.14, S D=1.95)$ than the longitudinal participants (see Table 1). Dropouts also reported significantly lower levels of social relationship quality $(M=3.13, S D=0.42$ vs. $M=3.19$, $S D=0.36)$, sense of control $(M=5.40, S D=1.07$ vs. $M=5.60$, $S D=0.95)$, and physical health $(M=-0.15, S D=0.87$ vs. $M=$ $0.04, S D=0.73$ ) than longitudinal participants

\section{Measures of Variables Used for Cluster Analyses}

At both measurement occasions, participants responded to the following question to rate their life satisfaction for three temporal foci: "Using a scale from 0 to 10 , where 0 means the worst possible life overall and 10 means the best possible life overall, how would you rate your life overall: these days (present), 10 years ago (past), and 10 years from now (future)?"

\section{Measures of Correlates of Subjective Change Profiles}

Demographic variables. Age, gender, marital status, educational level, and total household income were examined in relation to patterns of subjective life satisfaction change.

Sense of control. A composite scale was created by averaging Personal Mastery and Perceived Constraints subscales (Lachman $\&$ Firth, 2004), with a score ranging from 1 to 7 ( $\alpha=.84$ at T1 and .86 at T2) and higher scores indicating greater control.

Personality. Personality was measured with 30 attributes derived from existing Big Five trait inventories (Lachman \& Firth, 2004), with scores ranging from 1 to 4 . Because of a similar pattern of results across the personality factors, an overall personality composite was created for reasons of parsimony by averaging across all items (after reverse-scoring all items but those belonging to the Neuroticism subscale) so that a higher score would indicate a more positive overall personality profile, or Big One factor (see Musek, 2007; $\alpha=.84$ at T1 and .85 at T2).

Health. The health composite consisted of the number of functional limitations, chronic conditions, and acute conditions. A higher score reflects better health ( $\alpha=.70$ at $\mathrm{T} 1$ and .71 at T2).

Social relationship quality. Social support and strain items for family including spouse and friends were combined for a composite, with scores ranging from 1 to $4(\alpha=.87$ at T1 and T2).
Optimism. At T2, trait-like optimism was assessed using the 6-item Life Orientation Test (Scheier \& Carver, 1985), with response options ranging from 1 (agree a lot) to 5 (disagree a lot). Ratings were averaged after reverse scoring the optimistic attitude items $(\alpha=.79)$.

Cognitive mechanics. A cognitive mechanics composite was computed at T2 as the mean of five subtests of the Brief Test of Adult Cognition by Telephone (Lachman \& Tun, 2008; Tun \& Lachman, 2006).

\section{Analytic Strategy and Data Preparation}

We used a person-centered approach to address our research questions. Rather than classifying individuals into subgroups on the basis of only theoretical or clinical criteria, we selected cluster analysis as the most common implementation of an empirical approach to examine individual differences in a wholistic rather than a single-variable fashion (cf. Gerstorf et al., 2006). The central goal of cluster analysis is to group persons on the basis of their characteristics (i.e., ratings across a number of variables) so that within-group homogeneity is maximized, whereas betweengroup homogeneity is minimized (Bergman et al., 2003). In this study, the goal was to identify subgroups of individuals with a similar subjective change profile in life satisfaction at two measurement occasions. We therefore applied cluster analysis, separately for $\mathrm{T} 1$ and $\mathrm{T} 2$, to the three life satisfaction ratings of past, present, and future. Prior to analyses, we standardized the life satisfaction variables at each occasion using the grand mean and standard deviation across all items (i.e., three at each measurement occasion), capturing participants' overall satisfaction with life across the 9-year longitudinal assessment period. In addition, cases with values $>3 S D$ were excluded from the sample because cluster analysis is sensitive to outliers (Hair \& Black, 2000). Only respondents with complete data on all six life satisfaction variables, after outlier deletion, were retained in the final sample.

In a two-step clustering procedure (Hair \& Black, 2000), we first applied a hierarchical method with squared eucledian distances (Ward, 1963) in order to examine the theoretically and statistically most appropriate number of clusters. Ward's method (Ward, 1963) is an agglomerative method, in which each person initially starts out as its own cluster, and at each subsequent step, the two closest clusters (i.e., persons) are aggregated into a new and bigger cluster. This approach operationalizes the distance between two clusters as the sum of squares between two clusters summed across all variables. The Ward procedure was implemented using PROC CLUSTER in SAS 9.1 (SAS Institute, 20022003). A nonhierarchical method ( $k$ means) was applied next to optimize cluster membership assignment using the QUICK CLUSTER option in SPSS 14.0 (SPSS Inc., 2005). The cubic clustering criterion (Sarle, 1993) was used to inform decision making about the optimal number of clusters, because it is one of the most effective statistical criteria (Hair \& Black, 2000; Milligan

\footnotetext{
${ }^{2}$ Individuals excluded because of outlying values reported significantly lower life satisfaction at both measurement occasions regarding the present (T1: $M=5.76, S D=2.69 ; \mathrm{T} 2: M=5.91, S D=2.64)$, past $(\mathrm{T} 1: M=5.78$, $S D=3.09 ; \mathrm{T} 2: M=5.25, S D=3.12)$, and future (T1: $M=5.79, S D=$ 3.22; $\mathrm{T} 2: M=5.04, S D=3.51)$ than participants retained in the final sample (see Table 1 for means and standard deviations).
} 
Table 1

Means, Standard Deviations, and Intercorrelation of Sociodemographic and Biopsychosocial Correlates and Their Association With the Life Satisfaction Variables Entered Into the Cluster Analysis

\begin{tabular}{|c|c|c|c|c|c|c|c|c|c|c|c|c|c|c|c|}
\hline \multirow{2}{*}{$\begin{array}{c}\text { Correlates and Clustering } \\
\text { Variables }\end{array}$} & \multicolumn{2}{|c|}{ Time 1 (T1) } & \multicolumn{2}{|c|}{ Time 2 (T2) } & \multirow[b]{2}{*}{1} & \multirow[b]{2}{*}{2} & \multirow[b]{2}{*}{3} & \multirow[b]{2}{*}{4} & \multirow[b]{2}{*}{5} & \multirow[b]{2}{*}{6} & \multirow[b]{2}{*}{7} & \multirow[b]{2}{*}{8} & \multirow[b]{2}{*}{9} & \multirow[b]{2}{*}{10} & \multirow[b]{2}{*}{11} \\
\hline & $M$ & $S D$ & $M$ & $S D$ & & & & & & & & & & & \\
\hline 1. Age & 47.01 & 12.24 & 55.94 & 12.19 & & -.09 & .04 & -.04 & .07 & -.05 & .09 & -.21 & .16 & - & - \\
\hline 2. Education & 7.18 & 2.48 & 7.35 & 2.53 & -.13 & & .32 & -.12 & -.03 & .17 & .11 & .20 & .01 & - & - \\
\hline 3. Income (\$) & $62,063.58$ & $49,779.83$ & $80,533.69$ & 5534.55 & -.25 & .33 & & -.12 & .28 & .15 & .08 & .14 & .05 & - & - \\
\hline 4. Gender $(\%$ female $)$ & 54.6 & & 54.6 & & -.03 & -.11 & -.09 & & -.09 & -.07 & .06 & -.17 & .04 & - & - \\
\hline 5. Marital status (\% married) & 72.9 & & 73.1 & & -.08 & .03 & .32 & -.15 & & .04 & -.03 & .04 & .09 & - & - \\
\hline 6. Sense of control & 5.59 & 0.95 & 5.59 & 0.96 & -.04 & .17 & .15 & -.08 & .08 & & .45 & .32 & .36 & - & - \\
\hline 7. Personality & 3.18 & 0.34 & 3.15 & 0.35 & .11 & .09 & .04 & .07 & -.02 & .49 & & .16 & .33 & - & - \\
\hline 8. Health ${ }^{\mathrm{a}}$ & -0.04 & 0.73 & -0.01 & 0.78 & -.28 & .23 & .21 & -.17 & .08 & .34 & .19 & & .20 & - & - \\
\hline 9. Social relations & 3.19 & 0.36 & 3.25 & 0.36 & .20 & .02 & .02 & .02 & .07 & .39 & .35 & .16 & & - & - \\
\hline 10. Optimism ${ }^{\mathrm{b}}$ & 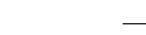 & 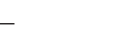 & 3.90 & 0.76 & .11 & .22 & .16 & -.01 & .08 & .57 & .49 & .26 & .36 & & - \\
\hline 11. Cognition ${ }^{\mathrm{b}}$ & - & - & 0.04 & 0.67 & -.43 & .42 & .27 & -.01 & .08 & .14 & .04 & .27 & -.03 & .13 & \\
\hline \multicolumn{16}{|l|}{ Life satisfaction } \\
\hline Past & 7.34 & 1.83 & 7.53 & 1.70 & & & & & & & & & & & \\
\hline $\mathrm{T} 1$ & & & & & .28 & -.03 & .08 & -.02 & .17 & .13 & .19 & .08 & .26 & - & - \\
\hline $\mathrm{T} 2$ & & & & & .31 & -.04 & -.02 & -.03 & .13 & .17 & .21 & .02 & .28 & .17 & -.16 \\
\hline Present & 7.95 & 1.37 & 7.98 & 1.39 & & & & & & & & & & & \\
\hline $\mathrm{T} 1$ & & & & & .20 & .02 & .16 & .01 & .21 & .38 & .35 & .20 & .48 & - & - \\
\hline $\mathrm{T} 2$ & & & & & .18 & .05 & .12 & .02 & .18 & .44 & .37 & .22 & .44 & .40 & -.04 \\
\hline Future & 8.50 & 1.27 & 8.19 & 1.60 & & & & & & & & & & & \\
\hline $\mathrm{T} 1$ & & & & & -.13 & .03 & .08 & .08 & .09 & .35 & .32 & .22 & .31 & - & - \\
\hline $\mathrm{T} 2$ & & & & & -.21 & .11 & .16 & .04 & .11 & .39 & .30 & .29 & .27 & .30 & .13 \\
\hline
\end{tabular}

Note. Correlations above the diagonal refer to T1 $(n=3,586)$, and those below the diagonal refer to T2 $(n=3,115)$. Correlations with $r \geq .04$ are significant at the $p<.05$ level. Correlations with $r \geq .06$ are significant at the $p<.01$ level.

${ }^{a}$ Health composite based on standardized variables separately for each measurement occasion. Descriptives for individual constructs included in health composites at $\mathrm{T} 1$ are $M(S D)=8.82(6.64)$ for acute health problems, $M(S D)=2.12(2.13)$ for chronic health problems, and $M(S D)=2.12(2.53)$ for functional limitations. At T2, the descriptives were $M(S D)=12.54$ (7.46) for acute health problems, $M(S D)=2.32(2.29)$ for chronic health problems, and $M(S D)=3.10$ (2.97) for functional limitations. ${ }^{\mathrm{b}}$ Optimism and cognition were only assessed at $\mathrm{T} 2$. T1 descriptives and intercorrelations can therefore not be computed as indicated by the dashes.

\& Cooper, 1987). The cubic clustering criterion represents the proportion of variance accounted for by the subgroups in relation to the dimensionality of the variance between groups. The cluster solutions were cross-validated by randomly splitting the sample in half. Kappa coefficients for multiple random splits were moderate to high, ranging between .46 and .95 for $\mathrm{T} 1$ and between .57 and .98 for $\mathrm{T} 2 .^{3}$

After identification of subgroups, we used a number of follow-up analyses to determine the validity of the subgroups in terms of differences on variables not included in the clustering procedure (Aldenderfer \& Blashfield, 1984; Hair \& Black, 2000). Multivariate analyses of variance (MANOVAs) were conducted to analyze subgroup differences in age and other sociodemographic as well as the biopsychosocial correlates at each measurement occasion. Repeated measures analyses of variance (ANOVAs) were applied to examine subgroup differences in longitudinal change in the biopsychosocial correlates. In a last step, apart from considering cluster subgroup membership separately at each measurement occasion as a between-person factor, we classified individuals according to whether they changed cluster membership between T1 and T2. Repeated measures ANOVA was then applied to examine differences in longitudinal biopsychosocial change as a function of consistent or inconsistent cluster group membership.

\section{Results}

Results are presented in four parts. First, we describe descriptive statistics on average levels of life satisfaction rated for the past, present, and future at both measurement occasions and the unique variance they accounted for in biopsychosocial correlates for the total sample. Next, we summarize the results of the cluster analysis, describing the number and profile of the identified subgroups. Third, we describe subgroup differences in level and longitudinal change in sociodemographic and biopsychosocial correlates. Last, we focus on inconsistencies in subgroup membership between the two measurement occasions and how inconsistency in cluster membership relates to longitudinal changes in biopsychosocial functioning.

\section{Descriptive Statistics for Past, Present, and Future Life Satisfaction in the Total Sample}

On average, participants perceived their life satisfaction to be fairly high and as slightly increasing across their personal lifetime at both T1, Wilk's $\lambda=.73, F(2,3629)=663.63, p<.01, \eta_{\mathrm{p}}^{2}=$ .27 , and T2, Wilk's $\lambda=.91, F(2,3629)=171.39, p<.01, \eta_{\mathrm{p}}^{2}=$ .09 (see Table 1). Post hoc pairwise comparisons indicated that the past differed significantly from the present and the present differed significantly from the future, but this latter difference was much smaller at T2 than at T1. At both measurement occasions, all three

\footnotetext{
${ }^{3}$ Note that of the total of 16 kappa coefficients obtained from four different random splits at each measurement occasion, which used values of each sample half as starting values for the clustering procedure within the other half and vice versa, only three were $<.60$.
} 
ratings were significantly correlated (within-occasion $r$ range $=$ .13-.62). The strongest association was between the present and the future, and the weakest relationship was between the past and the future.

We conducted hierarchical regression analyses to examine the amount of unique individual difference variance accounted for by each of the life satisfaction ratings compared with the others regarding the biopsychosocial correlates used later on to validate the identified cluster subgroups. As shown in Table 2, past and future ratings of life satisfaction accounted for small but significant additional amounts of unique variance over and above the present ratings for most of the biopsychosocial variables at both measurement occasions. A person's perception of past and future life satisfaction, beyond concurrent levels, thus provides some additional information, even though the effect sizes indicate that the effects are only small (Cohen, 1988). Given that they are based on single variables, however, it is nonetheless noteworthy to find such unique effects.

\section{Identification of Subgroups at T1 and T2}

A three-cluster solution was found to be the optimal representation of subgroup profiles at T1 and T2. Two of these clusters exhibited similar patterns of subjective life satisfaction change at both occasions, whereas the third group differed between baseline and followup. As a result of similarities in profiles for two out of the three subgroups identified, we describe subgroups conjointly for both measurement occasions whenever applicable (see Table 3 and Figure 1A for descriptives). Separate one-way MANOVAs at T1 and T2, which used the three life satisfaction ratings as the dependent variables and cluster membership as the independent variable, yielded a significant multivariate effect at both T1, Wilk's $\lambda=.18, F(6,7252)=1,612.21$, $p=.001, \eta_{\mathrm{p}}^{2}=.57$, and T2, Wilk's $\lambda=.18, F(6,7252)=1,682.94$, $p=.001, \eta_{\mathrm{p}}^{2}=.58$. Post hoc pairwise comparisons indicated that the three subgroups differed significantly on all profile-defining variables at both measurement occasions.
For the first subgroup (T1: $n=1,468,40.43 \%$; T2: $n=2,141$, $58.96 \%$ ) life satisfaction across all three temporal foci was between $0.5 S D$ and almost 1.5 SD above the sample means at T1 and T2. Pairwise comparisons from repeated measures ANOVA indicated that there were small but significant differences between past, present, and future satisfaction ratings, suggesting that this subgroup exhibited a slight upward trend from past to future at both $\mathrm{T} 1$ and $\mathrm{T} 2$, but the effect was small $\left(\eta_{\mathrm{p}}^{2}=.08\right.$ and .04 at T1 and T2, respectively). For descriptive purposes, this subgroup was labeled the continuous high profile.

The second subgroup reported life satisfaction in the past to be roughly $0.5 S D$ to $0.75 S D$ below the sample mean, a more or less average level of present life satisfaction, and about $0.5 S D$ above the sample mean for future life satisfaction (T1: $n=986,27.16 \%$; T2: $n=763,20.01 \%$ ). This subgroup reported substantial differences between past, present, and future satisfaction characterized by a clear upward trajectory $\left(\eta_{\mathrm{p}}^{2}=.67\right.$ and .53 at $\mathrm{T} 1$ and $\mathrm{T} 2$, respectively), so we labeled this cluster an incremental profile.

The third group at T1 $(n=1,177,32.42 \%)$ was between $0.5 S D$ to $1 S D$ below the sample mean across all life satisfaction variables, with the present rating being the lowest of the three ratings, thus showing a nonlinear subjective change pattern (effect size for within-group differences, $\eta_{\mathrm{p}}^{2}=.07$ ). This group is characterized by a profile that encompasses both growth and decline and thus a bidirectional change pattern. It was labeled the present low profile. In contrast, at T2, the third subgroup ( $n=727,20.02 \%)$ exhibited past, present, and future life satisfaction ratings that were between $0.5 S D$ to $2 S D$ below the sample mean, representing a clear downward pattern $\left(\eta_{\mathrm{p}}^{2}=.15\right)$. To reflect this, we labeled this group decremental profile.

In summary, we found evidence for both linear and nonlinear types of subjective change profiles representing various perceived life satisfaction trajectories. In contrast to our hypotheses, however, the majority of individuals appraised their life satisfaction to be (high and) rather stable as opposed to increasing. An incremen-

Table 2

Unique Variance Proportions of Each Temporal Life Satisfaction Rating Over and Above the Others in Predicting Individual Differences in Biopsychosocial Correlates

\begin{tabular}{|c|c|c|c|c|c|c|c|c|c|c|c|c|}
\hline \multirow{2}{*}{$\begin{array}{c}\text { Life } \\
\text { satisfaction }\end{array}$} & \multicolumn{2}{|c|}{ Control } & \multicolumn{2}{|c|}{ Personality } & \multicolumn{2}{|c|}{ Health } & \multicolumn{2}{|c|}{ Social relations } & \multicolumn{2}{|c|}{ Optimism } & \multicolumn{2}{|c|}{ Cognitive mechanics } \\
\hline & Unadjusted & Adjusted & Unadjusted & Adjusted & Unadjusted & Adjusted & Unadjusted & Adjusted & Unadjusted & Adjusted & Unadjusted & Adjusted \\
\hline \multicolumn{13}{|l|}{ Time 1} \\
\hline Total & $.17^{* * * * *}$ & $.21^{* * * * *}$ & $.14^{* * * * *}$ & $.17^{* * * * *}$ & $.06^{* * * * *}$ & $.17^{* * * * *}$ & $.23^{* * * * *}$ & $.24^{* * * * *}$ & & & & \\
\hline Present & $.04^{* * * *}$ & $.04^{* * * *}$ & $.02^{* * * * *}$ & $.02^{* * * *}$ & $<.01^{* * * * *}$ & $.01^{* * * *}$ & $.09^{\text {****** }}$ & $.08^{* * * *}$ & & & & \\
\hline Past & .00 & .00 & $<.01^{* * * * *}$ & $<.01^{* * * *}$ & .00 & $<.01^{* * * * *}$ & $.01^{* * * * *}$ & $<.01^{* * * * *}$ & & & & \\
\hline Future & $.02^{* * * *}$ & $.02^{* * *}$ & $.02^{* * * *}$ & $.02^{* * * *}$ & $.02^{* * * *}$ & $.01^{* * * *}$ & $<.01^{* * *}$ & $<.01^{* * * *}$ & & & & \\
\hline \multicolumn{13}{|l|}{ Time 2} \\
\hline Total & $.22^{* * * *}$ & $.24^{* * *}$ & $.15^{* * * *}$ & $.17^{* * * *}$ & $.09^{* * * *}$ & $.22^{* * * *}$ & $.20^{* * * *}$ & $.22^{* * * *}$ & $.17^{* * * *}$ & $.22^{* * * *}$ & $.06^{* * * *}$ & $.33^{* * * *}$ \\
\hline Present & $.05^{* * * *}$ & $.05^{* * *}$ & $.03^{* * * *}$ & $.02^{* * * *}$ & $<.01^{* * * *}$ & $.02^{* * * *}$ & $.07^{* * * * *}$ & $.05^{* * * *}$ & $.06^{* * * *}$ & $.04^{* * * *}$ & $.01^{* * * * *}$ & .00 \\
\hline Past & .00 & $<.01$ & $.01^{* * * *}$ & $.01^{* * * *}$ & $<.01^{*}$ & .00 & $.01^{* * * *}$ & $.01^{* * * *}$ & .00 & .00 & $.02^{* * * *}$ & $<.01^{*}$ \\
\hline Future & $.02^{* * * *}$ & $.01^{* * * *}$ & $.01^{\text {**** }}$ & $.01^{* * *}$ & $.04^{* * * *}$ & $.01^{\text {****** }}$ & .00 & $<.01^{\text {***** }}$ & $.01^{\text {***** }}$ & $.01^{* * * *}$ & $.03^{\text {**** }}$ & .00 \\
\hline
\end{tabular}

Note. Coefficients for the three temporal life satisfaction ratings represent the variance accounted for by each temporal rating after holding the other two temporal ratings constant. Unadjusted indicates that three life satisfaction ratings were the only predictors included in the hierarchical regression analyses; Adjusted indicates that the hierarchial regression models were controlled for age, gender, education, income, and marital status (entered in the first step of the regression analyses).

${ }^{*} p<.05 .{ }^{* *} p<.01{ }^{* * *} p<.001$. 
Table 3

Descriptives of Cluster Defining Variables at Time 1 (T1) and Time 2 (T2)

\begin{tabular}{|c|c|c|c|c|c|c|c|c|}
\hline \multirow[b]{2}{*}{ Clusters at $\mathrm{T} 1$} & \multicolumn{2}{|c|}{$\begin{array}{l}\text { Continuous high } \\
\text { profile }\end{array}$} & \multicolumn{2}{|c|}{ Incremental profile } & \multicolumn{2}{|c|}{ Present low profile } & \multirow[b]{2}{*}{$F(2,3628)$} & \multirow[b]{2}{*}{$\eta_{p}^{2}$} \\
\hline & $M$ & $S D$ & $M$ & $S D$ & $M$ & $S D$ & & \\
\hline Past life satisfaction & $0.76_{a}$ & 0.91 & $-2.73_{b}$ & 1.43 & $-0.42_{c}$ & 1.04 & 2918.51 & $.62^{* * * * *}$ \\
\hline Present life satisfaction & $1.03_{\mathrm{a}}$ & 0.75 & $-0.23_{\mathrm{b}}$ & 1.13 & $-0.97_{c}$ & 1.23 & 1274.29 & $.41^{* * * * *}$ \\
\hline \multirow[t]{2}{*}{ Future life satisfaction } & $1.34_{\mathrm{a}}$ & 0.66 & $0.85_{b}$ & 0.91 & $-0.61_{c}$ & 1.18 & 1529.01 & $.46^{* * * *}$ \\
\hline & \multicolumn{2}{|c|}{$\begin{array}{l}\text { Continuous high } \\
\text { profile }\end{array}$} & \multicolumn{2}{|c|}{ Incremental profile } & \multicolumn{2}{|c|}{ Decremental profile } & & \\
\hline Clusters at $\mathrm{T} 2$ & $M$ & $S D$ & $M$ & $S D$ & $M$ & $S D$ & $F(2,3628)$ & $\eta_{\mathrm{p}}^{2}$ \\
\hline Past life satisfaction & $0.53_{a}$ & 0.93 & $-2.61_{b}$ & 1.25 & $-0.73_{c}$ & 1.39 & 2301.78 & $.56^{* * * *}$ \\
\hline Present life satisfaction & $0.76_{a}$ & 0.85 & $-0.29 \mathrm{~b}$ & 1.31 & $-1.62_{c}$ & 1.05 & 1590.82 & $.47^{* * * *}$ \\
\hline Future life satisfaction & $0.91_{a}$ & 0.89 & $0.73_{b}$ & 0.94 & $-2.08_{c}$ & 1.46 & 2346.64 & $.56^{* * * *}$ \\
\hline
\end{tabular}

Note. Variables were $z$ score standardized using the sample mean and standard deviation of the grand mean across all six life satisfaction variables $(M=$ $7.91, S D=1.02$ ). Means in the same row that do not share subscripts differ at $p<.001$. Means in bold are at least $0.25 S D$ above or below the overall sample mean. $N=3,631$.

**** $p<.001$.

tal profile was found for about as many individuals as a V-shaped bidirectional or decremental subjective change profile.

\section{Subgroup Differences in Sociodemographic and Biopsychosocial Functioning at Baseline (T1) and at 9-Year Longitudinal Follow-Up (T2)}

Subgroup differences in sociodemographic status and change. Subgroup differences in sociodemographic variables were examined using a one-way MANOVA with age, education, and income as the dependent variables and cluster membership as the independent variable (see Table 4 and Figure 1B). Results yielded a significant multivariate effect at T1, Wilk's $\lambda=.93, F(6,7238)=$ 45.60, $p<.001, \eta_{\mathrm{p}}^{2}=.036$, and T2, Wilk's $\lambda=.91, F(6,7244)=$ $\left.56.83, p<.001, \eta_{\mathrm{p}}^{2}=.045\right)$. In line with our expectations, effect sizes and $F$ statistics from pairwise comparisons from univariate follow-up ANOVAs showed age to be most important in distinguishing subgroups across the sociodemographic characteristics. Also consistent with our hypotheses, the incremental profile subgroup was younger than the two other subgroups at each measurement occasion, being about $0.5 S D$ below the sample average. A further inspection of age-group frequencies in each cluster subgroup indicated that although at each age the majority of individuals belonged to the continuous high profile group, older adults were least likely to belong to the incremental groups and most likely to belong to the present low or decremental subgroups.

At T1, the continuous high subgroup reported the highest household income, whereas at $\mathrm{T} 2$, the decremental profile subgroup reported significantly lower income than both other groups. Education differentiated the subgroups only at $\mathrm{T} 2$, in which the decremental profile subgroup showed significantly lower levels than the two other subgroups. ${ }^{4}$ Gender and particularly marital status differences also emerged in a $\chi^{2}$ test, in that the continuous high subgroup was most likely to be married and the present low and decremental profile subgroups consisted of the smallest proportion of women.
As a brief follow-up, we also examined cluster subgroup differences with regard to changes in income and marital status. We found a marginally significant interaction between the T2 cluster subgroup and change in income, suggesting that the incremental subgroup at $\mathrm{T} 2$ experienced steeper increases in income from $\mathrm{T} 1$ to $\mathrm{T} 2$ than the two other subgroups. Regarding change in marital status, individuals in the incremental subgroup were more likely to get married between $\mathrm{T} 1$ and $\mathrm{T} 2$ than any other subgroup, whereas the continuous high subgroup was least likely to be continuously unmarried. On the basis of the observed sociodemographic disparities between subgroups, further analyses examining biopsychosocial correlates were adjusted for differences in sociodemographic characteristics.

Cluster differences in biopsychosocial status. We conducted a one-way MANOVA separately for T1 and T2 with cluster membership as the between-subjects variable and sense of control, health, personality, social relations, optimism (T2 only), and cognition (T2 only) as dependent variables, adjusting for sociodemographic characteristics.

The subgroups differed significantly on the status measures: T1, Wilk's $\lambda=.84, F(8,7150)=80.42, p<.001, \eta_{\mathrm{p}}^{2}=.083 ; \mathrm{T} 2$, Wilk's $\lambda=.82, F(12,6204)=55.05, p<.001, \eta_{\mathrm{p}}^{2}=.096(\mathrm{see}$ Table 5 for details). Effect sizes and $F$ statistics indicate that group differences were largest for sense of control, social relations, and personality (including optimism) and less strong for the health composite. Figure 1C illustrates subgroup profiles on the biopsychosocial variables adjusted for sociodemographic characteristics. The subgroup with the most favorable overall profile was the continuous high subgroup, with mean levels in biopsychosocial functioning reliably above the sample average. Thus, self-

\footnotetext{
${ }^{4}$ After controlling for income, the education effect was only marginally significant at $\mathrm{T} 1$ but remained significant at $\mathrm{T} 2$, whereas the effect for income remained significant at both measurement occasions even after controlling for education.
} 
A
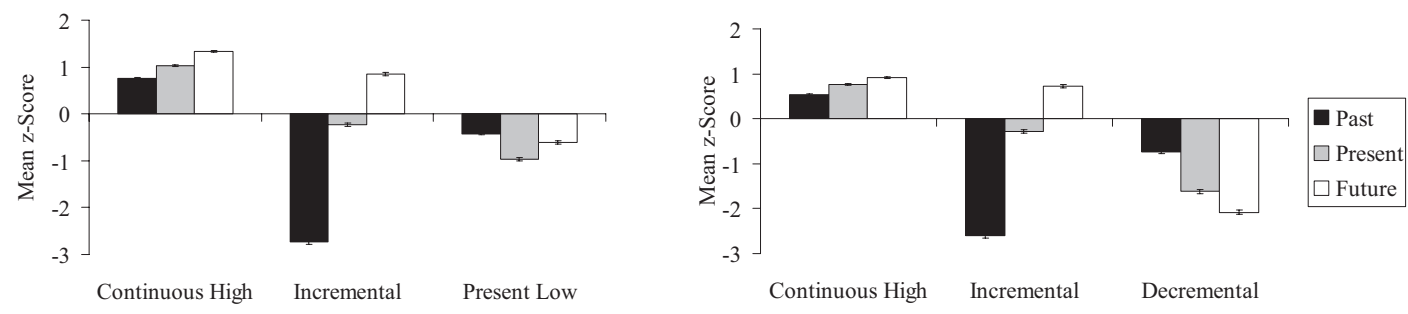

B
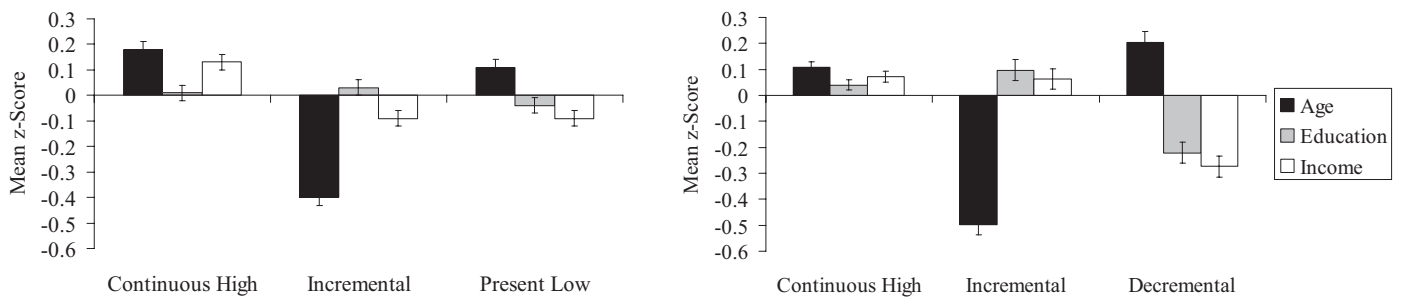

$\mathrm{C}$
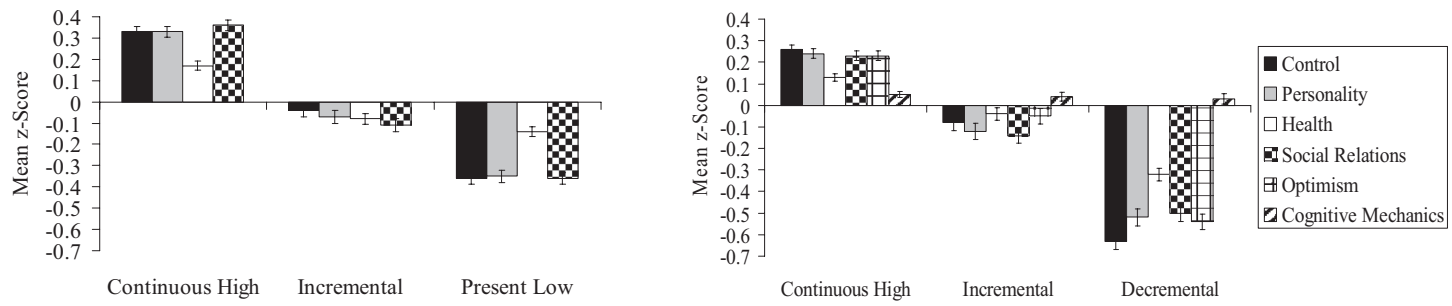

Figure 1. Cluster subgroup profiles of subjective life satisfaction change and sociodemographic as well as biopsychosocial correlates at Time 1 (T1) and Time 2 (T2). Error bars represent standard errors of the mean. A: Subgroup profiles on cluster defining variables at T1 and at T2. B: Subgroup differences in sociodemographic correlates. C: Subgroup differences in biopsychosocial correlates (adjusted for sociodemographic variables).

consistency rather than self-improvement in life satisfaction was most adaptive in this study.

Note that the subgroup displaying an incremental pattern of subjective life satisfaction change exhibited a profile of merely average or slightly below average functioning across correlates, including a measure of optimism assessed at T2 (rather than displaying high levels of optimism to match the optimistic subjective change trajectory in life satisfaction). The present low and particularly the decremental group showed the least favorable profile (with the exception of cognitive functioning, which did not differ across groups). It is noteworthy that the present low subgroup characteristics were similar to the decremental subgroup, even though individuals in this group perceived their life satisfaction to slightly increase from present to future, indicating prospective optimism despite subjective decline from the past. Overall, and largely consistent with the hypotheses, the biopsychosocial correlates differentiated the subgroups more strongly than sociodemographic variables.

Cluster differences in longitudinal change in biopsychosocial functioning. In order to examine whether subgroup differences in subjective life satisfaction change would also be reflected in differential change in biopsychosocial correlates, we conducted a 3 (cluster membership: continuous high, incremental, present low or decremental) $\times 2$ (measurement occasion: T1, T2) repeated mea- sures ANOVA for each of the four biopsychosocial correlates available at T1 and T2 (control beliefs, health, personality, social relations). Because of slight differences in cluster profiles identified at both measurement occasions, these analyses were carried out with cluster membership assignment for $\mathrm{T} 1$ and $\mathrm{T} 2$, while adjusting for sociodemographic differences.

Significant Cluster Membership $\times$ Time interactions suggested that the subgroups showed differential stability and change patterns regarding control: cluster membership at T1, $F(2,3580)=$ $13.15, p<.001, \eta_{\mathrm{p}}^{2}=.007$, and cluster membership at T2, $F(2$, $3579)=27.71, p<.001, \eta_{\mathrm{p}}^{2}=.015$; personality: cluster membership at $\mathrm{T} 1, F(2,3582)=5.03, p<.01, \eta_{\mathrm{p}}^{2}=.003$, and cluster membership at $\mathrm{T} 2, F(2,3582)=16.29, p<.001, \eta_{\mathrm{p}}^{2}=.009$; health: cluster membership at $\mathrm{T} 1, F(2,3614)=1.97, p=.14$, $\eta_{\mathrm{p}}^{2}=.001$, and cluster membership at T2, $F(2,3613)=9.57, p<$ $.001, \eta_{\mathrm{p}}^{2}=.005$; and social relations: cluster membership at T1, $F(2,3592)=13.20, p<.001, \eta_{\mathrm{p}}^{2}=.007$, and cluster membership at $\mathrm{T} 2, F(2,3591)=13.50, p<.001, \eta_{\mathrm{p}}^{2}=.007$.

Figure 2 illustrates the differential change patterns using the cluster membership breakdowns at T1 (A) and at T2 (B). The continuous high group and the incremental group showed somewhat similar change slopes but at different mean levels as discussed above. Both groups showed little change in control and personality but pronounced losses in health and reliable 
Table 4

Subgroup Differences in Sociodemographic Cluster Correlates at Time 1 (T1) and Time 2 (T2)

\begin{tabular}{|c|c|c|c|c|c|c|c|c|c|c|c|c|}
\hline \multirow[b]{2}{*}{ Clusters at $\mathrm{T} 1$} & \multicolumn{3}{|c|}{ Continuous high profile } & \multicolumn{3}{|c|}{ Incremental profile } & \multicolumn{3}{|c|}{ Present low profile } & \multirow[b]{2}{*}{$F(2,3621)$} & \multirow[b]{2}{*}{$\eta_{\mathrm{p}}^{2}$} & \multirow[b]{2}{*}{$\chi^{2}(2)$} \\
\hline & $M$ & $S D$ & $\%$ & $M$ & $S D$ & $\%$ & $M$ & $S D$ & $\%$ & & & \\
\hline Age & $0.18_{\mathrm{a}}$ & 1.02 & & $-0.40_{\mathrm{b}}$ & 0.85 & & $0.11_{\mathrm{a}}$ & 0.99 & & 116.62 & $.061^{* * * *}$ & \\
\hline Education & $0.01_{\mathrm{a}}^{\mathrm{a}}$ & 1.02 & & $0.03_{\mathrm{a}}$ & 0.96 & & $-0.04_{\mathrm{a}}$ & 1.01 & & 1.67 & .001 & \\
\hline Household income & $0.13_{\mathrm{a}}$ & 1.09 & & $-0.09_{\mathrm{b}}$ & 0.91 & & $-0.09_{\mathrm{b}}^{\mathrm{a}}$ & 0.94 & & 22.41 & $.012^{* * * *}$ & \\
\hline Female & & & 56.4 & & & 57.2 & & & 50.3 & & & $13.41^{\text {*** }}$ \\
\hline \multirow[t]{2}{*}{ Married } & & & 81.5 & & & 63.2 & & & 70.2 & & & $105.83^{* * * * *}$ \\
\hline & \multicolumn{3}{|c|}{ Continuous high profile } & \multicolumn{3}{|c|}{ Incremental profile } & \multicolumn{3}{|c|}{ Decremental profile } & & & \\
\hline Clusters at $\mathrm{T} 2$ & $M$ & $S D$ & $\%$ & $M$ & $S D$ & $\%$ & $M$ & $S D$ & $\%$ & $F(2,3624)$ & $\eta_{\mathrm{p}}^{2}$ & $\chi^{2}(2)$ \\
\hline Age & $0.11_{\mathrm{a}}$ & 0.99 & & $-0.50_{b}$ & 0.83 & & $0.20_{\mathrm{a}}$ & 1.03 & & 130.84 & $.067^{* * *}$ & \\
\hline Education & 0.04 & 1.00 & & $0.10^{\mathrm{b}}$ & 0.95 & & $-0.22_{\mathrm{b}}$ & 1.02 & & 23.42 & $.013^{* * * *}$ & \\
\hline Household income & $0.07_{\mathrm{a}}^{\mathrm{a}}$ & 1.03 & & $0.06_{\mathrm{a}}^{\mathrm{a}}$ & 0.98 & & $-0.27_{b}$ & 0.89 & & 35.00 & $.019^{* * * * *}$ & \\
\hline Female & & & 53.9 & & & 59.2 & & & 51.9 & & & $9.20^{*}$ \\
\hline Married & & & 79.8 & & & 63.9 & & & 63.0 & & & $119.45^{* * * *}$ \\
\hline
\end{tabular}

Note. All variables were standardized using $z$ scores within each measurement occasion (T1 and T2). Means in the same row that do not share subscripts differ at $p<.001$. Means in bold are at least $0.25 S D$ above or below the overall sample mean. At T1, $n=3,624$. At T2, $n=3,627$.

${ }^{*} p<.05$. ${ }^{* * * *} p<.001$.

increases in social relationship quality. In contrast, the present low subgroup showed slightly steeper gains in social relationship quality than the two other groups. Considering the relatively low mean levels in biopsychosocial correlates for the present low group in addition to the steep improvement in social relationship quality, we found support for the hypothesis of a mixed pattern of adaptive functioning in this subgroup. As expected, the decremental group showed the least adaptive pattern of change in the correlates, involving decreases in control, a less desirable personality profile over time, a steeper loss in health than both other groups, and stability as opposed to gains in social relationship quality. Given the 9-year time period between baseline and follow-up, it is not surprising that health-related losses were observable in all three groups. In summary, subgroup differences based on subjective life satisfaction change were related to differential patterns of 9-year change in biopsychosocial correlates.

Table 5

Subgroup Differences in Biopsychosocial Cluster Correlates Adjusted for Sociodemographic Characteristics at Time 1 (T1) and Time 2 (T2)

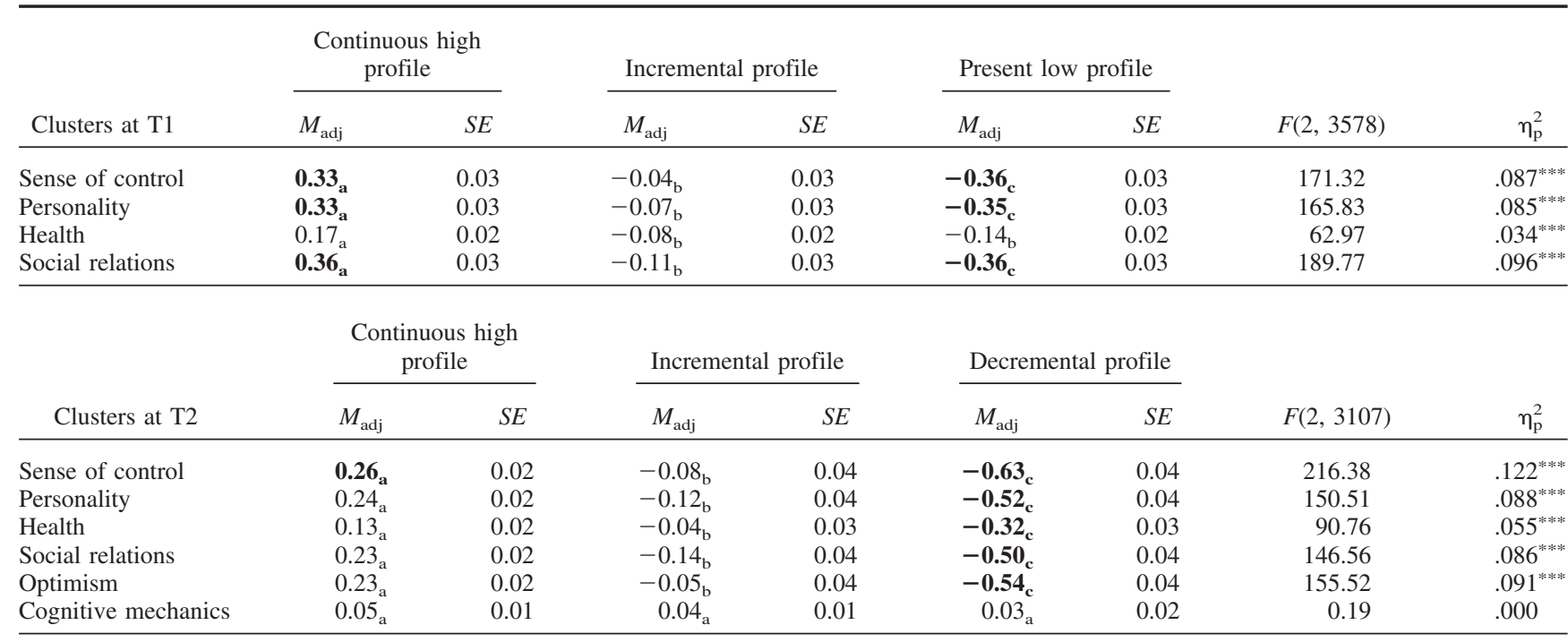

Note. All variables were standardized using $z$ scores within each measurement occasion (T1 and T2). Means in the same row that do not share subscripts differ at $p<.01$. Means in bold are at least $0.25 S D$ above or below the overall sample mean. Values represent marginal means after controlling for age, gender, education, income, and marital status at each measurement occasion. At T1, $n=3,586$. At T2, $n=3,115$.

**** $p<.001$. 
A

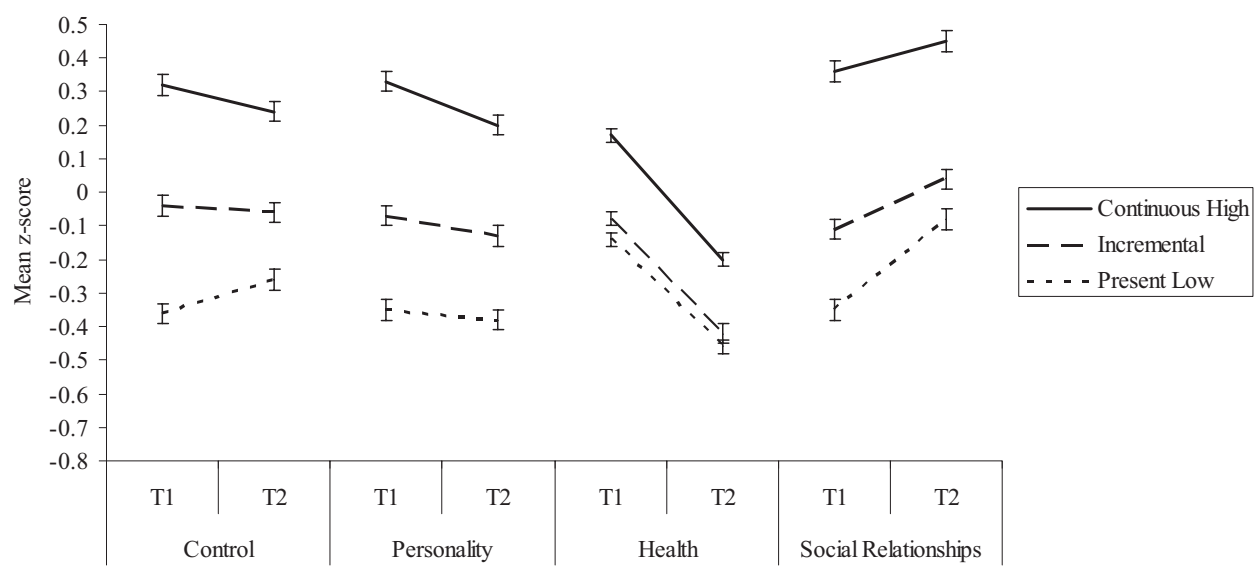

B

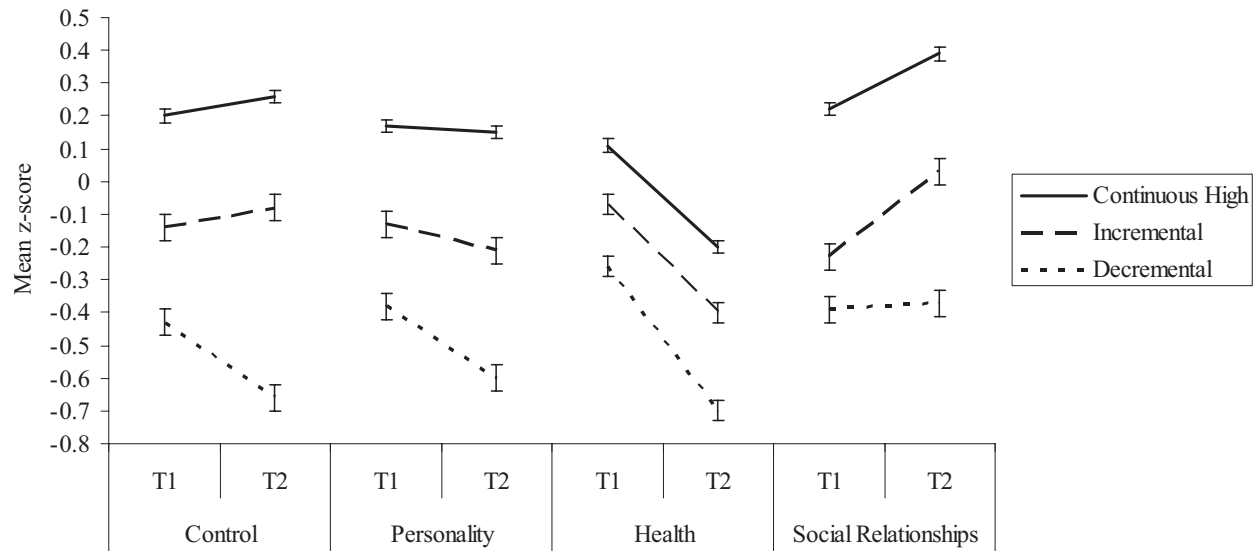

Figure 2. Differential 9-year change in biopsychosocial correlates as a function of cluster membership at Time (T1) and Time 2 (T2). Error bars represent standard errors of the mean. A: Subgroups based on T1 cluster membership. B: Subgroups based on T2 cluster membership.

Consistency Versus Inconsistency in Cluster Membership: Associations With Longitudinal Change in Biopsychosocial Correlates

Despite the similarity in two out of three subgroup profiles in subjective life satisfaction change between $\mathrm{T} 1$ and $\mathrm{T} 2$, not all individuals were classified into the same subgroup at both measurement occasions. Table 6 presents the percentage of participants who were classified into a given subgroup at $\mathrm{T} 2$, on the basis of their classification at T1. For example, of those participants classified into the continuous high profile group at $\mathrm{T} 1,80.2 \%$ also belonged to this cluster at T2. In contrast, only about one third of the incremental group at T1 was reclassified into this group 9 years later. As for the present low and decremental groups, "consistency" in membership refers merely to continuity in belonging to the third subgroup at both occasions. Across all three subgroups, about half of the sample was reclassified into the same cluster at $\mathrm{T} 2$ as at $\mathrm{T} 1(53.8 \%)$, which is quite a substantial number considering the 9-year time period ( $\kappa=.28, p<.001$ ), yet there is also evidence for a good deal of fluctuation in patterns of satisfaction.
To examine whether consistency versus inconsistency in cluster subgroup assignment was related to sociodemographic and biopsychosocial functioning, we created a between-subjects variable that classified individuals into one of three groups, on the basis of their T1 and T2 cluster membership outlined in Table 6: Consistent cluster membership was defined as being classified into a cluster with the same overall profile at both measurement occasions. Inconsistent cluster membership was defined as being classified into two subgroups with different profiles at both measurement occasions. On the basis of the mean-level differences between subgroups with regard to higher or lower levels of biopsychosocial functioning, we further differentiated the inconsistent cluster group into a more favorable and a less favorable subgroup: Less favorable changers were individuals who changed from being in the continuous high subgroup (T1) into one of the two other subgroups at T2, as were participants who belonged to the incremental subgroup at $\mathrm{T} 1$ but to the decremental subgroup at $\mathrm{T} 2$. In contrast, more favorable changers were individuals from the incremental and 
Table 6

Distribution of Cluster Membership at Time 2 (T2) on the Basis of Cluster Membership at Time 1 (T1)

\begin{tabular}{cccc}
\hline & \multicolumn{3}{c}{ Cluster membership at T2 } \\
\cline { 2 - 4 } Cluster membership at T1 & $\begin{array}{c}\text { Continuous } \\
\text { high }\end{array}$ & Incremental & Decremental \\
\hline Continuous high & & & \\
$n$ & 1177 & 149 & 142 \\
$\%$ & 80.2 & 10.1 & 9.7 \\
Incremental & 451 & 363 & 172 \\
$n$ & 45.7 & 36.8 & 17.4 \\
$\%$ & 513 & 251 & 413 \\
Present low & 43.6 & 21.3 & 35.1 \\
$n$ & & & \\
$\%$ &
\end{tabular}

Note. Percentages are based on T1 cluster membership. Thus, rows add up to $100 \%$.

present low subgroups at $\mathrm{T} 1$ who were assigned to the continuous high group at $\mathrm{T} 2$, as were individuals in the present low group (T1) who became members of the incremental subgroup (T2).

Table 7 provides descriptive information about differences in sociodemographic characteristics between the consistent and the two inconsistent groups. The multivariate effect of a one-way
MANOVA, which included age, education, and income as dependent variables and the cluster membership consistency classification (consistent, inconsistent-more favorable, inconsistent-less favorable) as the independent variable, was significant, Wilk's $\lambda=$ $.99, F(6,7238)=8.14, p<.001, \eta_{\mathrm{p}}^{2}=.007$, and the univariate follow-up ANOVAs suggested reliable subgroup differences in age (consistent $>$ inconsistent) and education (consistent, inconsistent-more favorable $>$ inconsistent-less favorable). Individuals changing into a less favorable subgroup were also less likely to be married. Given these slight differences in sociodemographic characteristics, subsequent examinations of differences in biopsychosocial status and change were adjusted for sociodemographic variables.

For ease of presentation, the lower part of Table 7 summarizes subgroup differences in baseline (T1) mean levels and change (i.e., difference scores based on T2 - T1) and the corresponding statistics for group comparisons. Together with Figure 3, these results indicate reliable differences in control, personality, health, and social relations at baseline as well as in 9-year change between individuals who belonged to the same subgroup at both occasions and those who did not. Moreover, the consistent membership subgroup showed little longitudinal biopsychosocial change, apart from the losses in health that were experienced by all groups and a slight improvement in social relationship quality. In contrast, those belonging to a less

Table 7

Baseline Characteristics and 9-Year Change in Biopsychosocial Correlates for Participants Who Were Consistent in Cluster Membership Versus Those Who Changed From Time 1 (T1) to Time 2 (T2)

\begin{tabular}{|c|c|c|c|c|c|c|c|c|c|c|c|c|}
\hline \multirow{3}{*}{$\begin{array}{l}\text { Sociodemographic } \\
\text { correlates }\end{array}$} & & & & \multicolumn{6}{|c|}{ Inconsistent } & \multirow[b]{3}{*}{$F(2,3621)$} & \multirow[b]{3}{*}{$\eta_{\mathrm{p}}^{2}$} & \multirow[b]{3}{*}{$\chi^{2}(2)$} \\
\hline & \multicolumn{3}{|c|}{ Consistent } & \multicolumn{3}{|c|}{ More favorable } & \multicolumn{3}{|c|}{ Less favorable } & & & \\
\hline & $M$ & $S D$ & $\%$ & $M$ & $S D$ & $\%$ & $M$ & $S D$ & $\%$ & & & \\
\hline Age at $\mathrm{T} 1$ & $0.08_{\mathrm{a}}$ & 1.01 & & $-0.11_{\mathrm{b}}$ & 0.94 & & $-0.07 \mathrm{~b}$ & 1.07 & & 15.50 & $.008^{* * * *}$ & \\
\hline Education at $\mathrm{T} 1$ & $0.02_{\mathrm{a}}$ & 1.01 & & $0.03_{\mathrm{a}}$ & 0.98 & & $-0.17_{\mathrm{b}}$ & 0.99 & & 7.29 & $.004^{* * * *}$ & \\
\hline Household income at $\mathrm{T} 1$ & $0.03_{\mathrm{a}}$ & 1.02 & & $-0.01_{\mathrm{a}}^{\mathrm{a}}$ & 0.98 & & $-0.11_{\mathrm{a}}$ & 0.97 & & 3.53 & $.002^{*}$ & \\
\hline Female & & & 54.8 & & & 53.0 & & & 58.3 & & & 3.85 \\
\hline Married & & & 74.3 & & & 72.5 & & & 67.6 & & & $8.69^{*}$ \\
\hline $\begin{array}{l}\text { Biopsychosocial } \\
\text { correlates }^{\mathrm{a}}\end{array}$ & $M_{\text {adj }}$ & $S E$ & & $M_{\text {adj }}$ & $S E$ & & $M_{\text {adj }}$ & $S E$ & & $F(2,3537)$ & $\eta_{\mathrm{p}}^{2}$ & \\
\hline Sense of control (T1) & $0.09_{\mathrm{a}}$ & 0.02 & & $-0.10_{\mathrm{b}}$ & 0.03 & & $-0.06_{\mathrm{b}}$ & 0.05 & & 14.89 & $.008^{* * * *}$ & \\
\hline $\begin{array}{l}\text { Change in control (T1- } \\
\mathrm{T} 2)\end{array}$ & $-0.05_{\mathrm{a}}^{\mathrm{a}}$ & 0.02 & & $0.17_{\mathrm{b}}$ & 0.03 & & $-0.27_{c}$ & 0.04 & & 44.05 & $.024^{* * * *}$ & \\
\hline Personality (T1) & $0.09 \mathrm{a}$ & 0.02 & & $-0.13_{\mathrm{b}}$ & 0.03 & & -0.02 & 0.05 & & 18.66 & $.010^{* * * *}$ & \\
\hline $\begin{array}{l}\text { Change in personality } \\
\text { (T1-T2) }\end{array}$ & $-0.10_{\mathrm{a}}^{\mathrm{a}}$ & 0.02 & & $0.03_{\mathrm{b}}$ & 0.02 & & $-0.26_{c}$ & 0.04 & & 24.00 & $.013^{* * * *}$ & \\
\hline Health (T1) & $0.04_{a}$ & 0.02 & & -0.02 & 0.02 & & $-0.09_{\mathrm{b}}$ & 0.04 & & 6.16 & $.003^{* * *}$ & \\
\hline $\begin{array}{l}\text { Change in health (T1- } \\
\text { T2) }\end{array}$ & -0.36 & 0.02 & & $-0.29_{b}$ & 0.02 & & $-0.43_{a}$ & 0.03 & & 7.49 & $.004^{* * *}$ & \\
\hline Social relations $(\mathrm{T} 1)$ & $0.10_{\mathrm{a}}$ & 0.02 & & $-0.11_{\mathrm{b}}$ & 0.03 & & $-0.11_{\mathrm{b}}$ & 0.05 & & 21.02 & $.012^{* * * *}$ & \\
\hline $\begin{array}{l}\text { Change in social } \\
\text { relations }(\mathrm{T} 1-\mathrm{T} 2)\end{array}$ & $0.12_{\mathrm{a}}^{\mathrm{a}}$ & 0.02 & & $0.30_{b}$ & 0.03 & & $-0.01_{\mathrm{c}}$ & 0.04 & & 24.45 & $.014^{* * * *}$ & \\
\hline
\end{tabular}

Note. T1 variables were standardized using $z$ scores $(M=0, S D=1)$, whereas T2 variables were standardized to the T1 mean and standard deviation to adequately represent change across time. Change scores were obtained for descriptive purposes by subtracting standardized scores for T1 from standardized T2 scores. Means in the same row that do not share subscripts differ at $p<.01$. Means in bold are at least $0.25 S D$ above or below the overall sample mean. For sociodemographic variables $n=3,624$. For biopsychosocial correlates $n=3,545$.

${ }^{a}$ Means adjusted for age, gender, education, income, and marital status.

${ }^{*} p<.05 .{ }^{* * *} p<.01{ }^{* * *} p<.001$. 


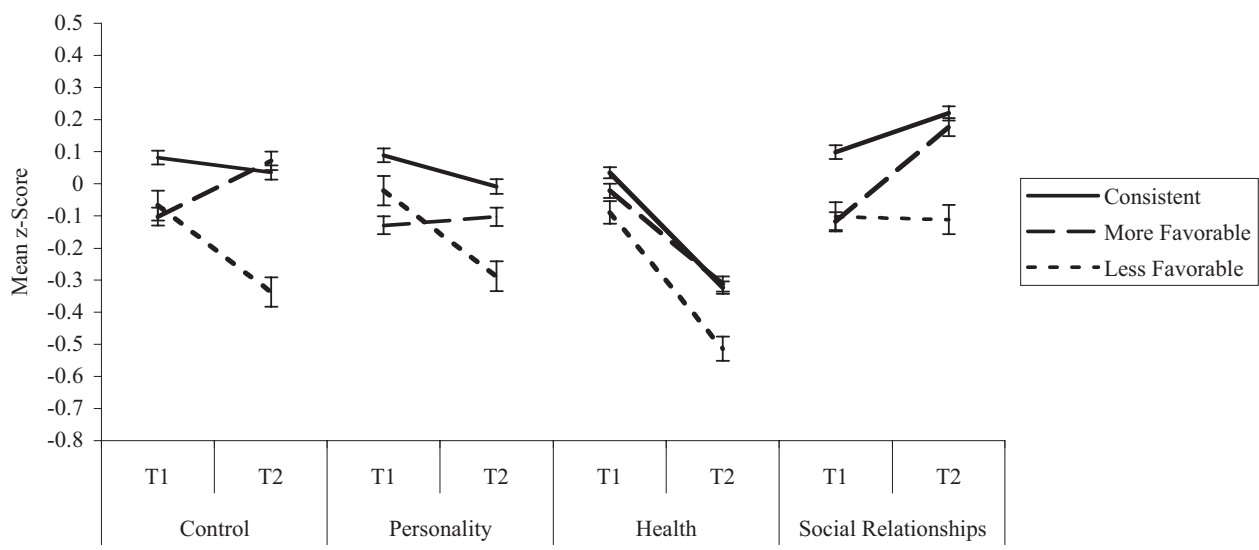

Figure 3. Differential 9-year change in biopsychosocial correlates as a function of consistency and inconsistency in cluster membership between Time 1 (T1) and Time 2 (T2). Error bars represent standard errors of the mean.

favorable subgroup also experienced longitudinal losses in all but one (social relations) domain, whereas individuals classified into a more favorable profile group at $\mathrm{T} 2$ showed increases in control and particularly in social relations. It thus appears that patterns of 9-year change in several indicators of adaptive functioning map onto subgroup differences in consistency and inconsistency in cluster membership and the direction of such inconsistency.

\section{Discussion}

The goal of the present study was to use a person-centered and wholistic approach to identify individual differences in types of profiles of subjective life satisfaction change. We used ratings of past, present, and future life satisfaction each provided at two measurement occasions spaced 9 years apart of over 3,000 adults aged 24 to 75 at T1 to identify subgroup differences in patterns of subjective change. Whereas most people report high levels of concurrent SWB and there is little evidence for remarkable changes across adulthood, we examined on the basis of life-span theories of motivation and self-concept theory whether subgroup differences in subjective change patterns exhibit greater agerelated and other sociodemographic differences than typically found regarding mean levels of life satisfaction. We also explored whether different profiles of subjective life satisfaction change would be related to theoretically proposed biopsychosocial correlates of concurrent adaptive functioning (Ko et al., 2007; Rowe \& Kahn, 1997) as well as 9-year longitudinal change in these correlates.

Consistent with prior research (Diener \& Diener, 1996; Pavot \& Diener, 1993), individuals in this national sample of adults, on average, reported moderate to high levels of life satisfaction. In addition, inspection of sample averages of past, present, and future life satisfaction at both measurement occasions suggested that individuals perceived their satisfaction as increasing from past to future (Aldwin et al., 1996; Newby-Clark \& Ross, 2003; Ryff, 1989). Using a person-centered approach, however, we identified four different linear and slightly nonlinear patterns of subjective change in satisfaction that represent various types of perceived life trajectories across one's personal lifetime, including stability as well as unidirectional (increase or decline) and bidirectional (increase and decline) change. In contrast to the average pattern, the largest percentage of individuals at both measurement occasions was found in a subgroup reporting high and relatively stable life satisfaction. Furthermore, of those patterns representing change, not all were in the direction of improvement. Rather, we also found decline patterns and a profile encompassing perceptions of decline from the past and increase regarding the future.

The person-centered approach, in which the joint pattern of past, present, and future life evaluations was considered for each individual, thus extends previous research on concurrent SWB and sample average subjective change patterns. Findings also complement longitudinal studies showing little objective change in many aspects of SWB (Diener \& Suh, 1998; Mroczek \& Kolarz, 1998; see also Lachman, Röcke, Rosnick, \& Ryff, 2008) and qualify the notion that most people are continuously happy (Diener \& Diener, 1996; see also Bortner \& Hultsch, 1972, 1974; Fleeson \& Heckhausen, 1997).

How do we reconcile the apparent discordance between the relative longitudinal stability in high levels of SWB on the one hand and individuals' perception that their life satisfaction changes on the other hand? The subjective appraisal of self-related change may be rooted in implicit theories individuals hold about the development of various person characteristics (Ross, 1989; Ryff, 1991). When evaluating the present only, it seems that most individuals are quite satisfied with their life in general and with specific life domains (Diener \& Diener, 1996). Despite changes in life circumstances and age-related losses in health, for instance, individuals appear to successfully maintain a sense of well-being by adapting their inter- and intraindividual reference frames and through emotion regulation (Charles \& Carstensen, 2004; Diener, Lucas, \& Scollon, 2006; Lachman, 2004). These self-regulatory processes as well as contextual factors may not be considered sufficiently when evaluating one's past and future at a given point in time, leading to perceptions of past and future change that in fact do not always occur (e.g., T. D. Wilson \& Gilbert, 2005). Furthermore, reflections on the past and anticipation of the future may 
trigger two distinct human needs: Whereas subjective self-related change may be inconsistent with the need for self-consistency, self-related increases are likely to satisfy the need for growth and improvement (Keyes \& Ryff, 2000; see also Fleeson \& Heckhausen, 1997; Ryff, 1984, 1989; Thorne \& Klohnen, 1993).

The salience of each of these needs may differ as a function of several individual difference characteristics, including age. Even though older adults may be at least as satisfied with their present lives as young and middle-aged adults, we found older adults more likely to expect future declines in satisfaction (see also Lachman et al., 2008). These age-group differences are consistent with lifespan theories of motivation, which propose an age-related shift from orientations on growth to maintenance and avoidance of loss (Baltes et al., 2006; Freund, 2006; Lachman, 2004). In addition, the age differences found in our study are in line with the notion that future time perspective becomes more limited with age (Carstensen et al., 1999). Perceptions of decline in life satisfaction may also provide useful insights into the boundary conditions of self-related resilience, not only in objective but also in subjective stability and change in life satisfaction (Mroczek \& Spiro, 2005), when individuals transition into the later parts of (older) adulthood (Baltes \& Smith, 2003).

In line with our expectations, other nonpsychological, sociodemographic variables beyond age had little explanatory power regarding subgroup differences. In contrast, we found meaningful and consistent subgroup differences in a range of variables considered as indicators of adaptive functioning (Ko et al., 2007; Rowe \& Kahn, 1997; Smith \& Baltes, 1997). It is interesting to note that subgroup differences were found not only for baseline levels in biopsychosocial functioning but also for objective 9-year change patterns in these correlates. In other words, subgroup differences in profiles of subjective change were consistently related to differential longitudinal change in cross-disciplinary correlates. Given that these correlates were selected to represent psychological (personality, sense of control, optimism, cognition), physical (health), and interpersonal domains (social support), we conclude that subgroup differences in profiles of subjective life satisfaction change are associated with a broad range of personal resources rather than high versus low functioning in single domains. Sense of control and social relationship quality, followed by personality traits, were most important in determining subgroup differences.

Consistent with the proposition from self-concept theory (Keyes \& Ryff, 2000; see also Thorne \& Klohnen, 1993) that selfconsistency is an important aspect of a sense of identity and SWB, our findings suggest that a profile characterized by high and relatively stable life satisfaction represents the most adaptive subjective change pattern with regard to both status and longitudinal change in biopsychosocial functioning. Apart from selfconsistency, perceived improvements are central to one's SWB and can have important motivational implications (Bryant et al., 2005; Conway, 2005; Robinson \& Ryff, 1999; Sutin \& Robins, 2008). In our study, a subjective change pattern representing an increase in life satisfaction was characterized by slightly above average biopsychosocial functioning. In contrast, perceiving a decline from past to present, and especially from the present to the future, was associated with very low baseline functioning and longitudinal losses in biopsychosocial functioning. Surprisingly, the subgroup with a prototypical optimistic pattern of subjective change, namely, the incremental subgroup, reported belowaverage rather than high levels of trait-like optimism, whereas the continuous high subgroup reported the highest level on that trait. One possible reason for this result may be that despite the perception that life has become more and more satisfying from past to present (i.e., an optimistic subjective change pattern) and will continue to get better, this subgroup reports overall merely average but not very high life satisfaction. It is possible that, in order to be dispositionally optimistic, it is not sufficient to view life as increasingly satisfactory over time, but one needs a certain (i.e., above average) mean level of life satisfaction. Our findings extend previous work in that not only present evaluations of life satisfaction relate to adaptive functioning but subjective change profiles do as well.

\section{Limitations of the Present Study}

Several limitations of the present study should be acknowledged. Even though participants were originally part of a national sample, we analyzed a slightly positively selected subgroup of longitudinal participants with complete data. It is thus possible that more individuals would be found with a less adaptive pattern of subjective change at follow-up than at baseline in a less selective sample.

Our focus in this study was on life satisfaction as one aspect of SWB. Types of subjective change were identified on the basis of three single items. A useful extension to the present findings would be to examine other aspects of SWB (e.g., positive and negative affect) and broader measures of positive human adjustment (Ryff, 1989). It would also be desirable to use multi-item measures for each temporal focus. However, even though individual differences in trajectories may have been more robust using multiple items for past, present, and future appraisals, we feel confident about our findings because subgroups consistently differed in both concurrent levels and longitudinal change in biopsychosocial functioning. We also showed that consistencies and inconsistencies in cluster membership between baseline and follow-up were associated with meaningful patterns of differential change in biopsychosocial correlates. Lastly, we found that each of the three ratings referring to different points in a person's life time accounted for additional, albeit small, unique variance in adaptive functioning outcomes over and above the remaining two items.

Finally, it would be informative to link subgroup differences to differential survival. At present, however, not a sufficient number of MIDUS participants has dropped out as a result of mortality to conduct meaningful analyses. Such information, in addition to the cross-disciplinary correlates considered in the present study, would provide a fruitful avenue for future work on understanding the adaptive or maladaptive value of a given pattern of subjective stability versus change in life satisfaction (e.g., Gerstorf et al. 2006).

\section{Conclusion and Outlook}

The present results provide a framework for proceeding with future work aimed at characterizing and enhancing SWB in adulthood in the context of successful life-span development and aging. Previous research has demonstrated that using a more systemicwholistic perspective of successful development and aging, rather 
than focusing on individual variables, provides a more complete perspective on the components of a good life. Whereas this previous work sought to identify subgroups of individuals characterized by profiles of successful aging across a broad range of variables, followed by an examination of subgroup differences in SWB (Fiori et al., 2007; Gerstorf et al., 2006; Ko et al., 2007), the present study used the reverse approach by focusing on subgroup differences in profiles of subjective stability and change in life satisfaction and an analysis of such profile differences in a range of cross-disciplinary biopsychosocial variables.

Despite the impressive relative stability of individuals' average levels of SWB with age, subjective lifetime conceptions involving a focus on past reflection and future outlook, can add a rich, dynamic quality to the assessment of SWB. Most studies examining perceptions of change in SWB focus on mean differences between the different time perspectives or consider only concurrent levels (Heckhausen et al., 1989; Ryff, 1989). In the present study, this would have led to the conclusion that life satisfaction is largely stable and that the average subjective change pattern represents an increase. However, the use of cluster analysis revealed that between $40 \%$ and $60 \%$ of individuals at both measurement occasions were not adequately characterized by a stable pattern, and not everyone who perceived change also thought that things had gotten and would get better. As we found little evidence for nonlinear subjective change profiles in the current study, future research, preferably with multi-item indicators of retrospective, present, and prospective self-related assessments, could apply alternative analytic approaches, including latent growth curve analysis, to obtain a more fine-grained perspective on individual differences in subjective change trajectories within subgroups.

Subgroup differences in subjective change profiles were linked to age in ways consistent with life-span theories of motivation and future time perspective and were also related to functional status and 9 -year change in biopsychosocial functioning. For individuals to maintain a positive outlook on their life, intact social relations as well as a high sense of control are key ingredients, not only for the present but also for subjective lifetime reviews and projections. By identifying sociodemographic and biopsychosocial correlates of subjective changes and stability in life satisfaction, the results suggest directions for exploring interindividual differences in SWB and optimism within a life-span perspective.

\section{References}

Albert, S. (1977). Temporal comparison theory. Psychological Review, 84, 485-503.

Aldenderfer, M. S., \& Blashfield, R. K. (1984). Cluster analysis. Thousand Oaks, CA: Sage Publications.

Aldwin, C., Sutton, K., \& Lachman, M. E. (1996). The development of coping resources in adulthood. Journal of Personality, 64, 837-871.

Baltes, P. B., Lindenberger, U., \& Staudinger, U. M. (2006). Life span theory in developmental psychology. In W. Damon \& R. M. Lerner (Eds.), Handbook of child psychology: Vol. 1. Theoretical models of human development (6th ed., pp. 569-664). New York: Wiley.

Baltes, P. B., \& Smith, J. (2003). New frontiers in the future of aging: From successful aging of the young old to the dilemmas of the fourth age. Gerontology, 49, 123-135.

Baumgartner, H., Pieters, R., \& Bagozzi, R. P. (2008). Future-oriented emotions: Conceptualization and behavioral effects. European Journal of Social Psychology, 38, 685-696.
Bergman, L. R., Magnusson, D., \& El-Khouri, B. M. (2003). Studying individual development in an interindividual context: A person-oriented approach. Mahwah, NJ: Erlbaum.

Bortner, R. W., \& Hultsch, D. F. (1972). Personal time perspective in adulthood. Developmental Psychology, 7, 98-103.

Bortner, R. W., \& Hultsch, D. F. (1974). Patterns of subjective deprivation in adulthood. Developmental Psychology, 10, 534-545.

Brim, O. G., Ryff, C. D., \& Kessler, R. C. (2004). How healthy are we? A national study of well-being at midlife. Chicago: University of Chicago Press.

Broemer, P., Grabowski, A., Gebauer, J. E., Ermel, O., \& Diehl, M. (2008). How temporal distance from past selves influences self-perception. European Journal of Social Psychology, 38, 697-714.

Bryant, F. B., Smart, C. M., \& King, S. P. (2005). Using the past to enhance the present: Boosting happiness through positive reminiscence. Journal of Happiness Studies, 6, 227-260.

Carstensen, L. L., Isaacowitz, D. M., \& Charles, S. T. (1999). Taking time seriously: A theory of socioemotional selectivity. American Psychologist, 54, 165-181.

Charles, S. T., \& Carstensen, L. L. (2004). A life span view of emotional functioning in adulthood and old age. Advances in Cell Aging and Gerontology, 15, 133-162.

Cohen, J. (1988). Statistical power analysis for the behavioral sciences (2nd ed.). Hillsdale, NJ: Erlbaum.

Conway, M. A. (2005). Memory and the self. Journal of Memory and Language, 53, 594-628.

Costa, P. T., Jr., \& McCrae, R. R. (1994). Set like plaster? Evidence for the stability of adult personality. In T. F. Heatherton \& J. L. Weinberger (Eds.), Can personality change? (pp. 21-40). Washington, DC: American Psychological Association.

Diener, E., \& Diener, C. (1996). Most people are happy. Psychological Science, 7, 181-185.

Diener, E., Lucas, R. E., \& Scollon, C. N. (2006). Beyond the hedonic treadmill: Revising the adaptation theory of well-being. American Psychologist, 61, 305-314.

Diener, E., \& Seligman, E. P. (2002). Very happy people. Psychological Science, 13, 81-84.

Diener, E., \& Suh, M. E. (1998). Subjective well-being and age: An international analysis. In K. W. Schaie \& M. P. Lawton (Eds.), Annual review of gerontology and geriatrics (Vol. 17, 304-324). New York: Springer.

Fiori, K. L., Smith, J., \& Antonucci, T. C. (2007). Social network types among older adults: A multidimensional approach. Journal of Gerontology: Psychological Sciences, 62B, P322-P330.

Fleeson, W., \& Baltes, P. B. (1998). Beyond present-day personality assessment: An encouraging exploration of the measurement properties and predictive power of subjective lifetime personality. Journal of Research in Personality, 32, 411-430.

Fleeson, W., \& Heckhausen, J. (1997). More or less "me" in past, present, and future: Perceived lifetime personality. Psychology and Aging, 12, 125-136.

Freund, A. M. (2006). Age-differential motivational consequences of optimization versus compensation focus in younger and older adults. Psychology and Aging, 21, 240-252.

Gerstorf, D., Lövdén, M., Röcke, C., Smith, J., \& Lindenberger, U. (2007). Well-being affects changes in perceptual speed in advanced old age: Longitudinal evidence for a dynamic link. Developmental Psychology, 43, 705-718.

Gerstorf, D., Smith, J., \& Baltes, P. B. (2006). A systemic-wholistic approach to differential aging: Longitudinal findings from the Berlin Aging Study. Psychology and Aging, 21, 645-663.

Hair, J. F., \& Black, W. C. (2000). Cluster analysis. In L. G. Grimm \& P. R. Yarnold (Eds.), Reading and understanding more multivariate statistics (pp. 147-205). Washington, DC: American Psychological Association.

Heckhausen, J., Dixon, R., \& Baltes, P. B. (1989). Gains and losses in 
development throughout adulthood as perceived by different adult age groups. Developmental Psychology, 25, 109-121.

Hertzog, C., \& Nesselroade, J. R. (2003). Assessing psychological change in adulthood: An overview of methodological issues. Psychology and Aging, 18, 639-657.

Jones, S. C. (1973). Self- and interpersonal evaluations: Esteem theories versus consistency theories. Psychological Bulletin, 79, 185-199.

Keyes, C. L. M., \& Ryff, C. D. (2000). Subjective change and mental health: A self-concept theory. Social Psychology Quarterly, 63, 264-279.

Ko, K. J., Berg, C. A., Butner, J., Uchino, B. N., \& Smith, T. W. (2007). Profiles of successful aging in middle-aged and older adult married couples. Psychology and Aging, 22, 705-718.

Kunzmann, U., Little, T. D., \& Smith, J. (2000). Is age-related stability of subjective well-being a paradox? Cross-sectional and longitudinal evidence from the Berlin Aging Study. Psychology and Aging, 15, 511-526.

Lachman, M. E. (2004). Development in midlife. Annual Review of Psychology, 55, 305-331.

Lachman, M. E., \& Firth, K. M. P. (2004). The adaptive value of feeling in control during midlife. In O. G. Brim, C. D. Ryff, \& R. Kessler (Eds.), How healthy are we? A national study of well-being at midlife (pp. 320-349). Chicago: University of Chicago Press.

Lachman, M. E., Lewkowicz, C., Marcus, A., \& Peng, Y. (1994). Images of midlife development among young, middle-aged, and older adults. Journal of Adult Development, 1, 201-212.

Lachman, M. E., Röcke, C., Rosnick, C. B., \& Ryff, C. (2008). Realism and illusion in Americans' temporal views of their life satisfaction: Age differences in reconstructing the past and anticipating the future. Psychological Science, 19

Lachman, M. E., \& Tun, P. A. (2008). Cognitive testing in large-scale surveys: Assessment by telephone. In D. Alwin \& S. Hofer (Eds.), Handbook on cognitive aging: Interdisciplinary perspectives (pp. 506522). Thousand Oaks, CA: Sage.

Magnusson, D. (1998). The logic and implication of a person approach. In R. B. Cairns, L. R. Bergman, \& J. Kagan (Eds.), Methods and models for studying the individual (pp. 33-63). Thousand Oaks, CA: Sage.

Marmot, M. G., Ryff, C., Bumpass, L., Shipley, M. J., \& Marks, N. F. (1997). Social inequalities in health: Next questions and converging evidence. Social Science and Medicine, 44, 901-910.

McFarland, C., Ross, M., \& Giltrow, M. (1992). Biased recollections in older adults: The role of implicit theories of aging. Journal of Personality and Social Psychology, 62, 837-850.

Milligan, G. W., \& Cooper, M. C. (1987). Methodology review: Clustering methods. Applied Psychological Measurement, 11, 329-354.

Mroczek, D. K., \& Kolarz, C. M. (1998). The effect of age on positive and negative affect: A developmental perspective on happiness. Journal of Personality and Social Psychology, 75, 1333-1349.

Mroczek, D. K., \& Spiro, A., III. (2005). Change in life satisfaction during adulthood: Findings from the Veterans Affairs Normative Aging Study. Journal of Personality and Social Psychology, 88, 189-202.

Musek, J. (2007). A general factor of personality: Evidence for the Big One in the five-factor model. Journal of Research in Personality, 41, 1213-1233.

Myers, D. G., \& Diener, E. (1995). Who is happy? Psychological Science, $6,10-19$.

Newby-Clark, I. R., \& Ross, M. (2003). Conceiving the past and future. Personality and Social Psychology Bulletin, 29, 807-818.

Pavot, W., \& Diener, E. (1993). Review of the Satisfaction With Life Scale. Psychological Assessment, 5, 164-172.

Pavot, W., Diener, E., \& Suh, E. (1998). The Temporal Satisfaction With Life Scale. Journal of Personality Assessment, 70, 340-354.

Robinson, M. D., \& Ryff, C. D. (1999). The role of self-deception in perceptions of past, present, and future happiness. Personality and Social Psychology Bulletin, 25, 596-608.

Rodin, J., Timko, C., \& Harris, S. (1985). The construct of control: Biological and psychosocial correlates. In C. Eisdorfer, M. P. Lawton, \&
G. L. Maddox (Eds.), Annual review of gerontology and geriatrics (pp. 3-55). New York: Springer.

Ross, M. (1989). Relation of implicit theories to the construction of personal histories. Psychological Review, 96, 341-357.

Ross, M., \& Wilson, A. E. (2000). Constructing and appraising past selves. In D. L. Schacter \& E. Scarry (Eds.), Memory, brain, and belief (pp. 231-258). Cambridge, MA: Harvard University Press.

Rowe, J. W., \& Kahn, R. L. (1997). Successful aging. The Gerontologist, $37,433-440$

Ryff, C. D. (1984). Personality development from the inside: The subjective experience of change in adulthood and aging. In P. B. Baltes \& O. G. Brim Jr. (Eds.), Life-span development and behavior (Vol. 6, pp. 243-279). Orlando, FL: Academic Press.

Ryff, C. D. (1989). In the eye of the beholder: Views of psychological well-being among middle-aged and older adults. Psychology and Aging, 4, 195-210

Ryff, C. D. (1991). Possible selves in adulthood and old age: A tale of shifting horizons. Psychology and Aging, 6, 286-295.

Ryff, C. D., \& Singer, B. H. (1998). Middle age and well-being. In H. S. Friedman (Ed.), Encyclopedia of mental health (pp. 707-719). San Diego, CA: Academic Press.

Sarle, W. S. (1983). Cubic clustering criterion (Tech. Rep. No. A-108) Cary, NC: SAS Institute.

Scheier, M. F., \& Carver, C. S. (1985). Optimism, coping and health: Assessment and implications of generalized outcome expectancies. Health Psychology, 4, 219-247.

Sedikides, C., \& Gregg, A. P. (2008). Self-enhancement: Food for thought. Perspectives on Psychological Science, 3, 102-116.

Smith, J., \& Baltes, P. B. (1997). Profiles of psychological functioning in the old and oldest old. Psychology and Aging, 12, 458-472.

Staudinger, U. M., Fleeson, W., \& Baltes, P. B. (1999). Predictors of subjective physical health and global well-being during midlife: Similarities and differences between the U.S. and Germany. Journal of Personality and Social Psychology, 76, 305-319.

Staudinger, U. M., Freund, A. M., Linden, M., \& Maas, I. (1999). Self, personality, and life regulation: Facets of psychological resilience in old age. In P. B. Baltes \& K. U. Mayer (Eds.), The Berlin Aging Study: Aging from 70 to 100 (pp. 302-328.). New York: Cambridge University Press.

Sutin, A. R., \& Robins, R. W. (2008). Going forward by drawing from the past: Personal strivings, personally meaningful memories, and personality traits. Journal of Personality, 76, 631-663.

Thorne, A., \& Klohnen, E. (1993). Interpersonal memories as maps for personality consistency. In D. C. Funder, R. D. Parke, C. TomlinsonKeasey, \& K. Widaman (Eds.), Studying lives through time: Personality and development (pp. 223-253). Washington, DC: American Psychological Association.

Tun, P. A., \& Lachman, M. E. (2006). Telephone assessment of cognitive function in adulthood: The Brief Test of Adult Cognition by Telephone (BTACT). Age and Ageing, 35, 629-632.

U.S. Census Bureau. (2008). Current populations survey. Retrieved January 14,2008 , from http://www.census.gov/cps/

Ward, J. H. (1963). Hierarchical grouping to optimize an objective function. Journal of the American Statistical Association, 58, 236-244.

Wilson, A. E., \& Ross, M. (2000). The frequency of temporal-self and social comparisons in people's personal appraisals. Journal of Personality and Social Psychology, 78, 928-942.

Wilson, T. D., \& Gilbert, D. T. (2005). Affective forecasting: Knowing what to want. Current Directions in Psychological Science, 14, 131-134.

Woodruff, D. S., \& Birren, J. E. (1972). Age changes and cohort differences in personality. Developmental Psychology, 6, 252-259.

Received July 18, 2007

Revision received June 16, 2008

Accepted June 23, 2008 